\title{
NEPED - An Integrated Development Project, and Its Role in Preservation of Indigenous Knowledge in Nagaland
}

\author{
Merensangla Longkumer ${ }^{1}$, A. K. Makar ${ }^{2}$ \\ ${ }^{1}$ Guest faculty, Dept. of Rural Development and Planning, SASRD, Nagaland University \\ ${ }^{2}$ Professor, Faculty member, Dept. of Rural Development and Planning, SASRD, Nagaland University
}

\begin{abstract}
The state of Nagaland inhabited by 16 major tribes has a rich source of Indigenous knowledge and practices of agriculture as the state consists of tribal inhabitants each with their own unique identity, customs and traditions. The cultural diversity of Nagaland makes it important to be aware of the local customs and practices, as different tribes have different ways of doing things. One thing though they have in common is the close relationship they share with the nature, and their cultures are deeply rooted to the biodiversity of the land. Any developmental effort should build upon the indigenous customs and practices of the local people. Keeping this in mind, the first ever externally - aided project in Nagaland,_NEPED, a registered society supported by Government of Nagaland (GoN) was formed in the year 1995. The society has already implemented programmes in three phases. The first phase was called Nagaland Environmental Protection and Economic Development (NEPED I). The second phase was Nagaland Empowerment of People through Economic Development (NEPEDII). And the third phase was also called Nagaland Empowerment of people through Economic Development (NEPED III). NEPED is the only ever project that had given utmost importance in preservation of the indigenous knowledge and practices of the region through collection and documentation of the indigenous practices from different villages across Nagaland.
\end{abstract}

Keywords: Indigenous knowledge, NEPED

\section{Introduction}

Naga society was and continues to be predominantly agrarian. Agriculture is the main land use and occupation in Nagaland. There are 16 officially recognised tribes and numerous sub-tribes in Nagaland. Each tribe and sub-tribe has its own unique sets of customs, practices and beliefs. This diversity is reflected in the different designs and motifs on their shawls, baskets, machetes (daos), etc where the designs distinctly identifies the tribe. Traditional farmers have adopted and adapted, looking at what nature gives them and devising indigenous systems that follow ecological principles while meeting basic needs for food, fuel and housing materials. The practise of slash and burn agriculture in Nagaland locally known as 'Jhum', a word derived from the Assamese language meaning "collective work" where vegetation is slashed, burned, tilled and sown and after a year or two of culturing, the land is left fallow for some years to regain its fertility, was productive and has been meeting the household needs of the Nagas. But rapid population growth in Nagaland had deteriorated the soil and the forests biodiversity gradually deteriorated. However the jhum cultivation is a part of the Naga tradition and so it could not be eliminated. So with a view to help farmers improve the land use system, the Nagaland Environmental Protection and Economic Development (NEPED I) was started in 1995 and successfully culminated in 2000. Integration of agro forestry into jhum cultivation was the approach used to improve land management.

The second phase of NEPED, Nagaland Empowerment of People through Economic Development (NEPED II) was formulated with the same acronym NEPED, begun in 2001 and culminated in 2006 in 104 villages. Overall, the programme aimed to build on and add value to the jhum system. This second phase aimed to develop options to strengthen natural resource management practices for improved food security through extension and intensification of the jhum and of agro forestry practices, to improve community capacity to use micro credit resources for developing agro based income generating activities and to improve market access for agro forestry produce. The third phase was started in 2006 and lasted till 2011 in 63 villages. It was also called Nagaland Empowerment of people through Economic Development (NEPED III). This phase concentrated on watershed activities, development of horticultural crops and piggery.

The premise of NEPED was to build upon traditional agriculture. Incorporating indigenous knowledge into a project also facilitates the empowerment and participation of the local people.

\section{Indigenous Knowledge in NEPED}

Indigenous knowledge are the local knowledge and practices that has its origin in that particular area that can serve as their identity and being handed down from generation to generation. Indigenous knowledge is a valuable resource that exists within a society. Any development initiated in that society should combine conventional know-how and modern techniques with local wisdom. However, the indigenous knowledge is gradually being forgotten due to a number of reasons such as:

1) Lack of written history or any other form of documentation.

2) Introduction of modern technology in the rural areas.

3) Increase in the population has lowered the 'carrying capacity' of the land. More people have become dependent on the land that they possess. This has 


\section{International Journal of Science and Research (IJSR) \\ ISSN (Online): 2319-7064 \\ Index Copernicus Value (2015): 78.96 | Impact Factor (2015): 6.391}

prompted the introduction of 'modern methods', often at the expense of traditional knowledge.

Based on this rationale, NEPED introduced the concept of having "local experts" assist in project activities. These experts share their wide range of indigenous knowledge with NEPED officers in implementing project activities and facilitating interaction between the communities. This is a unique strategy where indigenous knowledge is being used to complement scientific facts and facilitate NEPED's operations. The 'local experts' are a group of knowledgeable and respected men, drawn from various tribes, and are representatives of the cultural diversity of Nagaland.

NEPED has been working on collecting the indigenous knowledge from every project villages and taking it across the people to put it into practice according to the suitability of different villages.

NEPED is undertaking documentation of indigenous knowledge, ideas and practices because though Nagaland is rich in cultures and biodiversity, it has not yet been properly documented and most of the capacity to preserve it for the next generation of Nagas exist at the village level, in the elders and local experts who store an "oral botanical" record. By working directly with the men and women in the various villages of Nagaland, NEPED will help to ensure that the record will be saved for the next generations.

\section{Research Methodology}

There are eleven districts in Nagaland, viz,

1. Kohima 2.Dimapur 3. Wokha 4.Mokokchung 5.Zunheboto 6.Phek 7.Mon 8.tuensang 9.Peren 10.Longleng 11.Kiphire

Within Nagaland, the Human Development Index (State Human Development Report, 2004) is highest in Dimapur (0.73), followed by Mokokchung (0.71) and Phek district (0.450). Thus for the present study, based on these index, Dimapur, Mokokchung and Phek were selected.

Dimapur, being the gateway of the state has easy access to communication, transportation and infrastructures needed for any developmental activities. The state's only railway station and airport are located in the district. So based on its convenience and easy availability of resources for the research work, Dimapur was selected as one of the study area.

Mokokchung, one of the fast developing district of Nagaland and the cultural centre of the Aos. The Aos are considered the forward tribe of all the tribes among the Nagas. NEPED has been quiet successful in implementing its activities in Mokokchung.

Phek, one of the eleven district of Nagaland, lacking behind from other districts in many areas mainly because of poor transportation and communication, but yet the people are known for being hardworking, needs special focus and policy intervention to tap its vast unexplored resources. For the present study, Phek was selected as one of the study area to determine how much NEPED has succeeded in improving the economic status of the people in this backward area.

The basic criterion for the selection of the respondents is that one should be a beneficiary of NEPED. The respondents were selected randomly from the sample villages. From each selected villages, a total of 10 respondents were selected randomly. A total of 280 respondents were selected altogether.

The primary datas were collected directly from the selected respondents with the help of the structured schedule, by employing personal interview method.

The secondary datas were collected from the records of NEPED office and their various publications.

\section{Findings and Discussion}

The present study was conducted to investigate the preservation of indigenous knowledge by NEPED and how much it is being appreciated by the people. The indigenous knowledge which has been collected and documented by NEPED to keep it alive in this fast changing world where farming like any other practices is fast being replaced by the modern technologies has been taken across different villages by NEPED and thus in this present study, the indigenous knowledge has been listed and ranked according to the preferences of the respondents in all the three districts and ranked overall along with the percentages enclosed.

Table 1: Distribution of respondents based on the Indigenous Knowledge used by NEPED

\begin{tabular}{|c|c|c|c|c|c|}
\hline Sl.No & Features & \multicolumn{4}{|c|}{ Districts } \\
\hline & & PHEK & DIMAPUR & $R\left|\begin{array}{c}M O K O K C H U N \\
G\end{array}\right|$ & OVERALL \\
\hline 1 & Boulders \& Stone Barriers To Check Soil Erosion & $45(75)$ & $75(41.7)$ & $28(70)$ & $148(52.9)$ \\
\hline 2 & Locally Available Logs To Check Soil Erosion & $51(85)$ & $105(58.3)$ & $29(72.5)$ & $185(66.1)$ \\
\hline 3 & Coarse Mat Like Bamboo To Prevent Soil Erosion & $14(23.3)$ & $39(21.7)$ & $6(15)$ & $59(21.1)$ \\
\hline 4 & $\begin{array}{l}\text { Earthen Bunds To Check Erosion } \\
\end{array}$ & $2(31)$ & $75(41.7)$ & $29(72.5)$ & $135(48.2)$ \\
\hline 5 & $\begin{array}{l}\text { Intensification Of Jhum Fields With Annual Leg Crop? Use Of Leguminous Cover } \\
\text { Crops To Prevent The Loss Of Top Soil From Rain Action } \\
\end{array}$ & $33(55)$ & $145(80.6)$ & $40(100)$ & $218(77.9)$ \\
\hline 6 & Use Of Common Salt For Weed Suppression & 41(68.3) & 105(58.3) & $11(27.5)$ & $157(56.1)$ \\
\hline 7 & Controlling Thatch Grass Through Cassava & $2(3.3)$ & $146(81.1)$ & 0 & $148(52.9)$ \\
\hline 8 & Cut Leaves And Branches And Uprooted Weeds To Provide Green Manure & $39(65)$ & $146(81.1)$ & $20(50)$ & $205(73.2)$ \\
\hline 9 & Use Of Trenches To Stabilise The Steep Slope & $20(33.3)$ & $34(18.9)$ & $20(50)$ & $74(26.4)$ \\
\hline 10 & Tree Planting Below Contour Bunds & $38(63.3)$ & $109(60.6)$ & $23(57.5)$ & $170(60.7)$ \\
\hline 11 & Organic Manures & $18(30)$ & $110(61.1)$ & $9(22.5)$ & $137(48.9)$ \\
\hline 12 & Use Of Crops Across The Slopes To Check Erosion & $46(76.7)$ & $36(20.0)$ & $20(50)$ & $102(36.4$ \\
\hline
\end{tabular}

\section{Volume 6 Issue 7, July 2017}




\section{International Journal of Science and Research (IJSR) \\ ISSN (Online): 2319-7064}

Index Copernicus Value (2015): 78.96 | Impact Factor (2015): 6.391

\begin{tabular}{|c|c|c|c|c|c|}
\hline 13 & Planting Of Broom Grass Across The Slopes & 13(21.7) & 0 & $11(27.5)$ & $24(8.6)$ \\
\hline 14 & Planting Ofalder Stumps Enriches Soil Structures & $28(46.7)$ & 0 & $8(20)$ & $36(12.9)$ \\
\hline 15 & Planting Curcuma \& Hedychium Rhizomes To Prevent Erosion & 0 & 0 & 0 & 0 \\
\hline 16 & Use Of Hedgerows As Soil Riser & 0 & 0 & 0 & 0 \\
\hline 17 & Use Of Arhar As Strip Crop & $28(46.7)$ & 0 & $18(45)$ & $46(16.4)$ \\
\hline 18 & Fallow Management With Tithonia & 0 & 0 & 0 & 0 \\
\hline 19 & Use Of Wild Sunflower To Restore The Soil Back To Health In 2-3 Yrs Time & $17(28.3)$ & $32(17.8)$ & $17(42.5)$ & $66(23.6)$ \\
\hline 20 & Slashing, Burning,Hoeing \& Hand Weeding Of Weeds & $60(100)$ & $180(100)$ & $40(100)$ & $280(100)$ \\
\hline 21 & $\begin{array}{l}\text { Materials Like Leaves, Straws,Bamboo Splits, Bark Are Used As Mulch To Check } \\
\text { Weed Growth }\end{array}$ & $25(41.7)$ & $80(44.4)$ & $18(45)$ & $123(43.9)$ \\
\hline 22 & Thatch Control Through Tithonia & $60(100)$ & $180(100)$ & $40(100)$ & $280(100)$ \\
\hline 23 & Contour Trenching To Control The Flow Of Loose Soil & $47(78.3)$ & $38(21.1)$ & $27(67.5)$ & $112(40)$ \\
\hline 24 & Using Whole Bamboos To Control Soil Erosion In Jhum Field & $49(81.7)$ & $38(21.1)$ & $23(57.5)$ & $110(39.3)$ \\
\hline 25 & $\begin{array}{l}\text { Soil Furrows To Conserve Moisture \& Allowing Excessive Water To Flow } \\
\text { Downwards During Heavy Rain }\end{array}$ & $32(53.3)$ & $110(61.1)$ & $24(60)$ & $166(59.3)$ \\
\hline
\end{tabular}

*Figures in parentheses indicate percentage

When the respondents were asked about the use of boulders and stone barriers to check soil erosion, the percentage of preference were 75 percent in Phek, 41.7 percent in Dimapur, 70 percent in Mokokchung and overall, it was 52.9 percent. According to the respondents, the advantages of using boulders and stone barriers were that the materials were easily available and effective in checking erosion.

The percentage of preference of locally available logs to check soil erosion was 85 percent in Phek, 58.3 percent in Dimapur, 72.5 percent in Mokokchung and overall 66.1 percent. According to the respondents, the method of constructing mechanical barriers using locally available logs was found very effective in preventing soil erosion. The crops grown on these areas showed better growth and yield.

The percentage of preference of coarse mat like bamboo was 23.3 percent in Phek, 21.7 percent in Dimapur and 15 percent in Mokokchung. Overall, it was 21.1 percent. According to the respondents, the bamboos were cheap and abundantly available.

When the respondents were asked about the construction of earthen bunds, the percentage of preference were 31 percent in Phek, 41.7 percent in Dimapur and 72.5 percent in Mokokchung. Overall, it was 48.2 percent. The respondents were of the view that construction of such bunds can be labour intensive but at the same time the materials are locally available and a cheap method for erosion control.

The percentage of preference over the use of annual leguminous cover crops has been 55 percent in Phek, 80.6 percent in Dimapur and 40 percent in Mokokchung. Overall,it was 77.9 percent. According to the respondents, this practise has improved the soil fertility as the cover crops can fix atmospheric nitrogen in the soil and the land productivity has increased tremendously.

The percentage of preference for the use of common salt for weed suppression was 68.3 percent in Phek, 58.3 percent in Dimapur and 27.5 percent in Mokokchung. Overall, it was 56.1 percent. According to the respondents, the use of common salt has been probably the most effective weedicide for broad leaf weeds and safe and easy to use and eve drives away the leeches in the jhum fields.

The percentage of preference for controlling thatch grass through cassava was 3.3 percent in Phek, 81.1 percent in
Dimapur and 0 percent in Mokokchung. Overall, it was 52.9 percent. Thatch grass is an extremely troublesome weed and its weeding operations are very intensive and costly. But planting cassava has been helpful in suppressing the growth of thatch in the jhum fields. However, according to some of the respondents, they havent tried this method at all and it seemed to be quite labour intensive.

The percentage of preference for the use of cut leaves and branches and uprooted weeds for green manure were 65 percent in Phek, 81.1 percent in Dimapur and 50 percent in Mokokchung. Overall, it was 73.2 percent. The respondents were of the view that this practice had been quite economical and beneficial and easy to carry out.

When asked about the use of trenches to stabilise the steep slope, the percentage of preference was 33.3 percent in Phek, 18.9 percent in Dimapur and 50 percent in Mokokchung. Overall, it was 26.4 percent. According to the respondents, it's a little bit costly method but effective in stabilising the steep slope.

The percentage of preference for tree planting below contour bunds were 63.3 percent in Phek, 60.6 percent in Dimapur and 57.5 percent in Mokokchung. Overall, it was 60.7 percent. The respondents shared that the trees reduced loss of soil and nutrients, improvement or maintenance of organic matter and improvement of soil structure and waterholding capacity.

Organic manure such as bokashi was introduced to the farmers and the percentages of preference were 30 percent in Phek, 61.1 percent in Dimapur and 22.5 percent in Mokokchung. Overall, it was 48.9 percent. The farmers were of the view that availability of such manures had been something new and different to them but at the same time some of the respondents were not even aware of it.

The percentage of preference for the use of crops across the slopes to check erosion was 76.7 percent in Phek, 20 percent in Dimapur and 50 percent in Mokokchung. Overall, it was 36.4 percent. This practise not only prevented soil erosion but also helped conserve soil moisture and the leaves added organic matter to the soil. However, the respondents were of the view that the soil were disturbed when the root crops like tubers and bulbs were harvested.

\section{Volume 6 Issue 7, July 2017 www.ijsr.net}




\section{International Journal of Science and Research (IJSR) \\ ISSN (Online): 2319-7064 \\ Index Copernicus Value (2015): 78.96 | Impact Factor (2015): 6.391}

The percentage of preference for the planting of broom grass across the slopes are 21.7 percent in Phek, 0 percent in Dimapur and 27.5 percent in Mokokchung. Overall, it was 8.6 percent. The preference for this particular practice has been quite low because cultivation of broom grass, though its still going on, has declined to a great extent. The farmers are also apprehensive that the grass might hamper the main crops.

The practice of planting alder stumps is quite high in Phek with 46.7 percent, 0 percent in Dimapur and 20 percent in Mokokchung. Overall, it was 12.9 percent. The respondents of Dimapur were not much aware of this practice and were not much interested in it. However, the respondents shared that it enriches the soil structure with leaf litters and root nodules.

There is a nil preference of planting curcuma and hedychium rhizomes to prevent erosion and use of hedgerows as soil riser. These practices are quite preferred in other districts of Nagaland but there had been no preference in the selected study areas. According to the respondents, they were aware of this practise but these crops do not have any domestic or economic value.

The percentage of preference for the use of arhar as strip crop (strip crops are crops that are introduced in systematic bands of two or more rows, which alternate with the rows of main crops and are usually laid out across the slope) were 46.7 percent in Phek, 0 percent in Dimapur, the reason being not so suitable with the climatic conditions as it thrives well in dry, cool weather and it's not a traditional crop as well, 45 percent in Mokokchung and overall it was 16.4 percent. The respondents shared that soil erosion could be minimised due to soil binding by roots and trapping of run-off soil and also, both the grain and husk could be used ac concentrated feeds for cattle. However, the disadvantage of this practice is that it is not a usual traditional crops and a new practise to many farmers. The preference on fallow management with tithonia was 0 percent as the respondents were not much aware of this practice.

The use of Velvet bean (Mucuna Pruriens) for thatch control was 28.3 percent in Phek, 17.8 percent in Dimapur and 42.5 percent in Mokokchung. Overall, it was 23.6 percent. The beans could be used as vegetables and due to its dense foliage, it was considered good for controlling weeds such as thatch grass.

The percentage on preference for slashing, burning, hoeing and hand weeding of weeds were 100 /percent in all the three districts. So overall, it was 100 percent. According to the respondents, this practice is the usual, traditional and the cheapest method of weeding, though its time consuming. Inspite of all the modern techniques for weeding, it is the age old method preferred by the farmers all over.

The use of materials like leaves, bamboo splits, bark for mulching has been practicing by the farmers since long and it is one of the cheapest means to check weed growth as well as for soil moisture conservation. So, the percentages of preference were 41.7 percent in Phek, 44.4 percent in Dimapur and 45 percent in Mokokchung. Overall, it was 43.9 percent.

Thatch grass (Imperata cylindrica) is a perennial grass and one of the most obnoxious weeds in Nagaland and it is difficult to eradicate or even to control it. The respondents fully agreed $(100 \%)$ on the use of Tithonia (Tithonia diversifolia) for thatch control in all the three districts and shared that due to its dense foliage, Tithonia could helped in controlling the thatch grass and the leaves on decomposition added biomass to the soil.

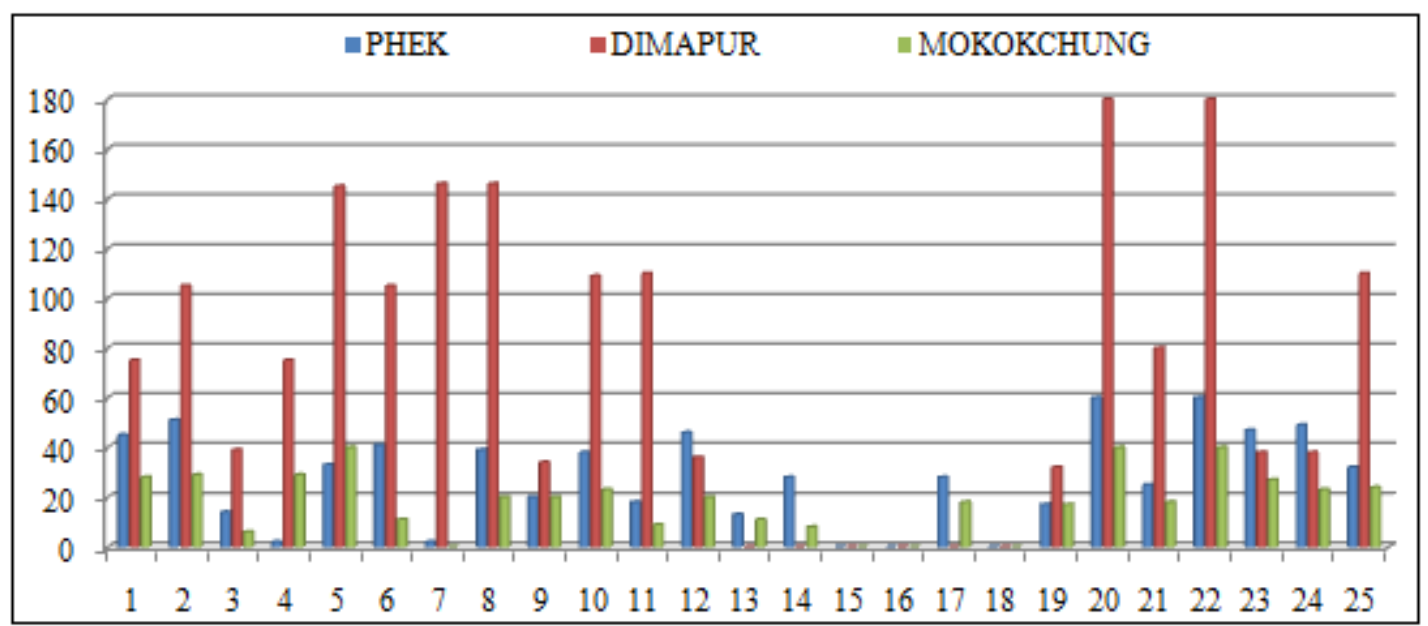

Figure 1: Distribution of respondents based on the Indigenous Knowledge used by NEPED 
International Journal of Science and Research (IJSR)

ISSN (Online): 2319-7064

Index Copernicus Value (2015): 78.96 | Impact Factor (2015): 6.391

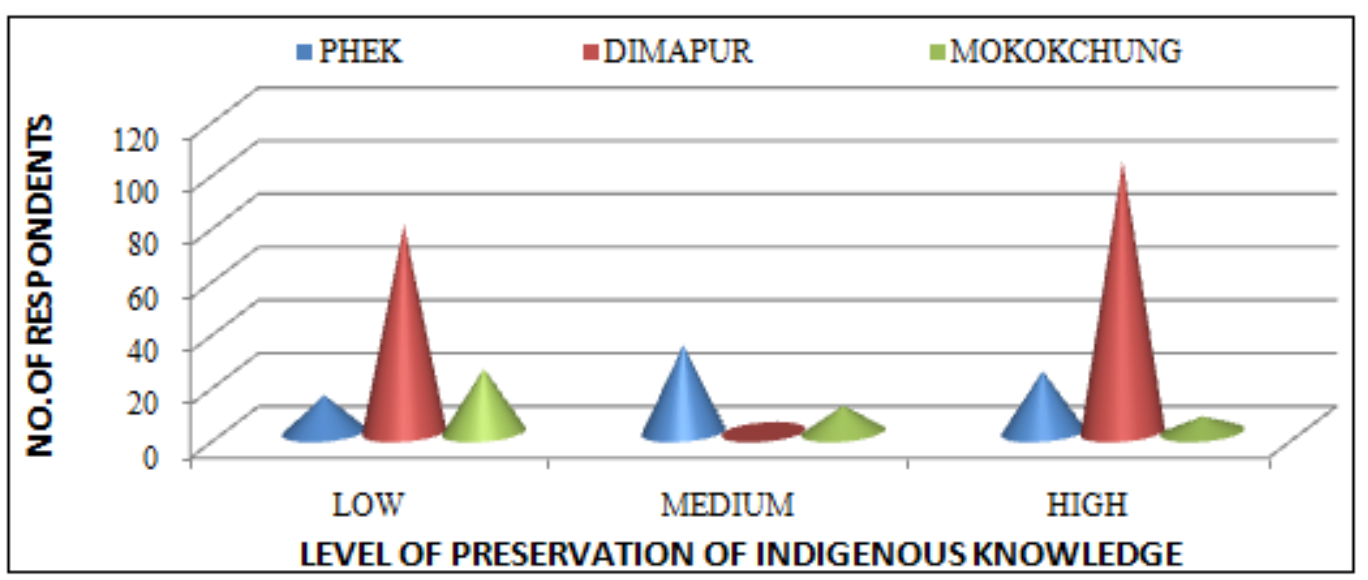

Figure 2: Level of preservation of Indigenous Knowledge

The percentage of preference for Contour trenching to control the flow of loose soil was 78.3 percent in Phek, 21.1 percent in Dimapur and 67.5 percent in Mokokchung. Overall, it was 40 percent. According to the respondents, it proved effective in controlling the flow of loose soil and the trapped soil was spread over to the other parts of the field.

The percentage of preference for using whole bamboos to control soil erosion was 81.7 percent in Phek, 21.1 percent in Dimapur, 57.5 percent in Mokokchung. Overall, it was 39.3 percent. It is a very common practise used by the farmers and is effective in controlling soil erosion, but the bamboos have to be replaced in every jhum cycle.

The percentage of preference on preparing soil furrows to conserve moisture and allowing excess flow downwards during heavy rain was 53.3 percent in Phek, 61.1 percent in Dimapur, 60 percent in Mokokchung. Overall, it was 59.3 percent.

Table 2: Level of preservation of Indigenous Knowledge

\begin{tabular}{|c|c|c|c|c|c|c|}
\hline \multirow{2}{*}{$\begin{array}{l}\text { Sl. } \\
\text { No }\end{array}$} & \multirow[t]{2}{*}{ Category } & \multirow{2}{*}{$\begin{array}{l}\text { Score } \\
\text { Range }\end{array}$} & \multicolumn{3}{|c|}{ Districts } & \multirow[t]{2}{*}{ Overall } \\
\hline & & & PHEK & DIMAPUR & MOKOKCHUNG & \\
\hline 1 & Low & $\begin{array}{l}\text { Upto } \\
33.59\end{array}$ & $\begin{array}{c}14 \\
(23.3)\end{array}$ & $\begin{array}{c}78 \\
(43.3)\end{array}$ & $\begin{array}{c}24 \\
(60)\end{array}$ & $\begin{array}{c}110 \\
(39.2)\end{array}$ \\
\hline 2 & Medium & $\begin{array}{l}33.59- \\
35.08\end{array}$ & $\begin{array}{c}33 \\
(55)\end{array}$ & 0 & $\begin{array}{l}10 \\
(25)\end{array}$ & $\begin{array}{c}56 \\
(20)\end{array}$ \\
\hline 3 & High & $\begin{array}{c}35.08 \& \\
\text { above }\end{array}$ & $\begin{array}{c}23 \\
(38.3)\end{array}$ & $\begin{array}{c}102 \\
(56.6)\end{array}$ & $\begin{array}{c}6 \\
(3.33) \\
\end{array}$ & $\begin{array}{c}114 \\
(40.71)\end{array}$ \\
\hline
\end{tabular}

$\mathbf{M}=36.1633 .5435 .2234 .34$

S.D $=.8743 .2367 .8253 .7404$

Table 2 revealed medium level $(55 \%)$ of preservation of indigenous knowledge in Phek, followed by high level $(38.3 \%)$ and low level $(23.3 \%)$ preservation of indigenous knowledge. Dimapur had high level $(56.6 \%)$ preservation of indigenous knowledge followed by 43.3 percent with low level preservation of indigenous knowledge. In Mokokchung, there had been low level 60\%) preservation of indigenous knowledge, followed by medium level of 25 percent and 3.33 percent with high level preservation of indigenous knowledge. Overall, the level of preservation of indigenous knowledge is high $(40.71 \%)$, followed by low level $(39.2 \%)$ and medium level $(20 \%)$.

It is evident from Table 2 and Figure 2 the high level of preservation of indigenous knowledge by NEPED. This is a commendable achievement for NEPED because many developmental activities by various departments might have brought positive changes in the rural areas but many ignore the importance of indigenous knowledge and the need to integrate it with the modern technology. The use of modern scientific techniques has replaced the use of indigenous knowledge to a great extent. So any development initiated in that society should combine conventional know-how and modern techniques with local wisdom. The incorporation of indigenous knowledge into a project could facilitate the empowerment of the local people and also it gives opportunity for equal participation of the people.

It is evident from Table 2 and Fig 2 that NEPED has worked well for the preservation of indigenous knowledge in Nagaland.

\section{Conclusion}

NEPED has emphasized and given much attention for the preservation of indigenous knowledge because of the cultural diversity of Nagaland and also, it is gradually being forgotten. No agencies and any department has ever given any focus on integrating the indigenous knowledge of the villagers with modern techniques so far. Realising the importance of indigenous knowledge in Naga customs and that it can be quite instrumental in empowering the local people, NEPED had taken utmost interests and initiation in preserving the indigenous knowledge by collecting and disseminating and documenting the indigenous knowledge and practices from different villages of Nagaland as different tribes and different villages have different ways of doing things.

\section{Suggestions for Further Research}

1) The study was limited to three districts only. Similar studies may be undertaken in other districts of Nagaland.

2) Further studies may be conducted to have an exhaustive and in-depth view on NEPED's policy on indigenous knowledge and traditional institution.

3) A comparative study may also be carried out between districts of Nagaland.

4) A detailed study on various constraints faced by the respondents could be made critically.

\section{Volume 6 Issue 7, July 2017 www.ijsr.net}




\section{References}

[1] NEPED and IIRR (1999) "Building upon traditional agriculture in Nagaland, India", N.V.Press, Kohima, Nagaland.

[2] Baerg R, Vettivel SK, Bagai DS. (2000) "Nagaland Environmental Protection and Economic Development Project Performance Assessment".

[3] NEPED (2003) "Watershed Project Report for NEPED Project Area 2006-2011"

[4] NEPED (2006) "Adding Value to Shifting cultivation in Nagaland India”, N.V.Press, Kohima, Nagaland.

\section{Author Profile}

Dr. Merensangla Longkumer is a Guest faculty, Department of Rural Development \& Planning, School of Agricultural Sciences \& Rural Development, Nagaland University, Medziphema Campus and

Prof. A.K.Makar is the Head of the Department, Department of Rural Development \& Planning, School of Agricultural Sciences \& Rural Development, Nagaland University, and Medziphema Campus. 